\title{
Peran Vlog dalam Perkembangan Pola Pikir Siswa Sekolah Menengah Kejuruan Teknologi Informasi Komputer Darussalam Medan
}

\section{The Role of Vlog on The Development of Thought Children's Patterns at Information of Computer Technology Vocational High School Darussalam Medan}

\author{
Muya Syaroh Iwanda Lubis*, Asrindah Nasution \& Muhammad Luthfi
}

Ilmu Komunikasi, Fakultas Ilmu Sosial dan Politik, Universitas Dharmawangsa Indonesia

Diterima:06 Maret 2020; Disetujui: 19 April 2020; Dipublish: 27 April 2020

\begin{abstract}
Abstrak
Artikel atau tulisan ini bertujuan untuk mengembangkan bakat siswa ke dunia Vlog, tidak sembarangan dan memberikan dampak negatif, serta melatih pola pikir anak remaja untuk terus berkembang sesuai perubahan dan perkembangan zaman tanpa mengesampingkan peran moral di dalamnya. Guna mendekati masalah ini dipergunakan acuan teori dari buku Teknologi Komunikasi oleh Nurudin. Datadata dikumpulkan melalui wawancara, observasi dan dokumentasi. Teknik analisis data secara Kualitatif menggunakan: Reduksi, penyajian dan penarikan kesimpulan. Kajian ini menyimpulkan bahwa Peran Vlog banyak diminati oleh kalangan siswa di Indonesia khususnya SMK TIK Darussalam. Sehingga perkembangan pola Pikir mereka menjadi berkembang ketika harus memikirkan video Vlog apa yang baik untuk dipublikasikan ke masyarakat. Dengan melihat Vlog yang dihasilkan orang lain, siswa/siswi mampu mengasah perkembangan pola Pikirnya sehingga membuat mereka menjadi mengerti video Vlog yang positif atau negatif untuk dipublikasikan. Dengan begitu apa yang mereka kerjakan memiliki nilai positif untuk dirinya, sekolah dan masyarakat.
\end{abstract}

Kata Kunci: Vlog, Perkembangan, Pola, Pikir

\begin{abstract}
This article or article aims to develop students' talent into the world of Vlogs, not to be careless and have a negative impact, and to train the mindsets of adolescents to continue to develop according to the changes and developments of the times without ignoring the moral role in them. To approach this problem the theoretical reference from the Communication Technology book by Nurudin was used. Data collected through interviews, observation and documentation. Qualitative data analysis techniques using: Reduction, presentation and conclusion drawing. This study concludes that the role of Vlogs is in great demand by students in Indonesia, especially SMK TIK Darussalam. So that the development of their mindset develops when they have to think of what Vlog videos are good for public publication. By seeing Vlogs produced by others, students are able to hone the development of their thought patterns so that they can understand Vlog videos that are positive or negative for publication. That way what they do has a positive value for themselves, the school and the community
\end{abstract}

How to Cite: Lubis, M.S.I, Nasution, A \& Luthfi, M (2020). Peran Vlog dalam Perkembangan Pola Pikir Siswa Sekolah Menengah Kejuruan Teknologi Informasi Komputer Darussalam Medan. Jurnal Simbolika: Research and Learning in Comunication Study 6(1): 59-64 


\section{PENDAHULUAN}

Perhatian kita terhadap pekembangan teknologi komunikasi sangat dibutuhkan mengingat begitu besarnya pengaruh media sosial yang sudah ada, mampu membuat seseorang bisa salah mempersepsikan apa yang diinformasikan. Publik perlu dan butuh memperhatikan hal-hal yang pantas atau tidak untuk ditiru dan diterima secara mentah-mentah setiap informasi yang ada. Sebuah definisi singkat dibuat oleh Harold D Lasswell bahwa cara yang tepat untuk menerangkan suatu tindakan komunikasi ialah menjawab pertanyaan siapa yang menyampaikan, apa yang disampaikan, melalui saluran apa, kepada siapa dan apa pengaruhnya (Cangara, 2002).

Informasi dari setiap media sosial mempengaruhi pola fikir setiap orang, terutama anak remaja setingkat SMK TIK. Mereka akan dengan mudah menerima informasi begitu saja tanpa dicerna dan di cari kebenarannya terlebih dahulu. Sehingga tidak jarang banyak anak remaja setingkat SMK TIK berubah perilaku, norma dan nilai, serta sikap mereka mengikuti perkembangan zaman yang mereka dapat dari sosial media (Darmawan, 2013).

Beragam penggunaan media sosial pada saat ini, juga terlihat, misalanya media sosial untuk pemberdayaan perempuan, sosial dan manyarakat (Barus, 2015), untuk media promosi pariwisata (Lubis, dkk, 2020). Hal tersebut menjadi dampak positif dari medai sosial yang sekarang berkembang di masyarakat. Teknologi komunikasi seperti sosial media, youtobe misalnya. Aplikasi yang sangat cepat ditiru oleh setiap generasi muda saat ini. Perkembangan yang cepat, informasi yang mudah didapat serta keuntungan yang didapat membuat banyak orang beralih ke aplikasi tersebut dan salah satunya adalah dengan membuat Vlog. satunya adalah dengan membuat Vlog (Mulyana, 2002).

Vlog, istilah yang sedang tren khususnya di kalangan penonton YouTube, semakin membombardir konten di situs video milik Google tersebut. Tiap hari, mungkin ada banyak video yang merekomendasikan konten Vlog di layanan berbagi video itu. Media komunikasi Vlog misalnya secara umum merupakan sebuah sarana atau alat yang dipakai sebagai penyampaian pesan dari komunikator kepada khalayak. Vlog juga menjadi salah satu komunikasi langsung dengan menggunakan media (Liliweri, 2012). Media sangat dominan dalam berkomunikasi ialah pancaindra manunsia seperti mata, telinga (Heryanto, 2015). Alih-alih menggunakan teknologi untuk kehidupan sehari-hari, justru memberi sisi negative yang berwujugd kepada dampak ketergantungan remaja terhadap media social. Untuk itulah, ada banyak upaya yang dilakukan oleh masyarakat dengan salah satunya, membatasi, mengawasi dan memberikan literasi tentang penggunaan media social secara terus menerus (Kurniawati, 2017; Syaroh, 2018)

Menurut informasi CNN Indonesia.com diunduh tanggal 16 Oktober 2019 http://www. Survey peminat Vlog, menjelaskan Google Indonesia pun mencatat, sejak tahun 2014 saat Vlog mulai booming, ada peningkatan hingga 600 persen video yang diunggah ke YouTube. Walaupun sebetulnya, Google sendiri tidak mengkategorikan Vlog secara khusus. "Sebetulnya Vlog adalah ternd yang general. YouTube mengkategorikan video berdasarkan genre (atau tipe 
konten), seperti misalnya Comedy, Music, Gaming, dan banyak lagi. Ini kami lakukan supaya audiens bisa dengan mudah menemukan konten yang mereka suka dan butuhkan.

Tingkat Kesiapterapan Teknologi (TKT) dalam penelitian ini diharapkan siswa dapat menggunakan kamera dengan baik dalam mengambil gambar dalam pembuatan video. Selain itu, siswa dapat mengenal jenis kamera yang baik, menggunakan teknologi komunikasi tidak hanya untuk komunikasi saja tetapi juga dalam menggunakan alat teknologi yang berkembang.

Tujuan di atas, menjelaskan bahwa jika dalam pembuatan Vlog, teknik pengambilan gambar juga dibutuhkan guna memberikan hasil yang maksimal dan baik kepada masyarakat.

Teknologi komunikasi yang digunakan oleh Siswa/siswi SMK TIK nantinya juga akan memberikan dampak positif bagi masyarakat yang juga ingin mempelajari tentang Vlog. Di mana menurut beberapa ahli bahwa Teknologi Komunikasi merupakan proses dimana pihak-pihak saling menggunakan informasi dengan untuk mencapai tujuan bersama dan komunikasi merupakan kaitan hubungan yang ditimbulkan oleh penerus rangsangan dan pembangkitan balasannya (Nurudin, 2007).

$$
\text { Pengguna Vlog biasanya }
$$

menampilkan kehidupan mereka, pamer, membuat konten yang tidak bermutu, ikutikutan agar kelihatan eksis, membuat konten kurang menarik, bahkan bisa menjadi ajang ejek-mengejek satu sama lainnya. Hal inilah, yang menjadikan Vlog menjadi satu sisi negatif bagi orang yang membuat dan melihatnya terutama bagi anak remaja SMKS TIK, yang baru merasakan tumbuh kembang dan masamasa remaja.

Penjelasan di atas merupakan keuntungan dari segi finansial. Selain itu ada keuntungan lain juga yang bisa didapatkan misalnya lebih menarik dan seru untuk dilakukan dibanding dengan blogging dalam bentuk tulisan saja. Bahkan lebih jauh lagi ini bisa menjadikan kita popular karena sering muncul di internet dan banyak dikenal sehingga bagus juga untuk karir anda ke depannya.

\section{METODE PENELITIAN}

Penelitian ini dilakukan dengan pendekatan kualitatif. Penelitian dengan pendekatan kualitatif digunakan karena peneliti bermaksud mengamati subjek dan objek penelitian agar dapat memahami perilaku, persepsi, motivasi dan tindakan dari masyarakat (Sugiyono, 2007). Sumber data diperoleh dari siswa/siswi SMK TIK Darussalam (Ahmadi, 2014).

Teknik pengambilan data menggunakan teknik wawancara, observasi dan dokumentasi. Sedangkan analisis data dalam penelitian ini meliputi tiga jalur, yaitu: reduksi data, penyajian data dan penarikan kesimpulan yang ketiganya sebagai sirklus dalam pengambilan kesimpulan (Singarimbun, 1995).

\section{HASIL DAN PEMBAHASAN}

SMK TIK Darussalam memiliki 3 jurusan unggulan di bidang Teknik Komputer dan Jaringan, Multimedia, dan Otomatisasi Tata Kelola Perkantoran. SMK TIK Darussalam sebagai lembaga pendidikan yang dapat diakui sebagai pengembang generasi yang profesional 
dan berbasis IT serta dapat bersaing dalam Pasar Kerja Global.

SMK TIK Darussalam memiliki siswa yang sangat kreatif, seperti siswa yang sudah menciptakan Vlog yang memiliki content "peduli Sampah". Siswa tersebut sangat ingin memberikan kesadaran masyarakat pentingnya menjaga kebersihan lingkungan. Hal ini di sebabkan betapa tidak sehatnya lingkungan hidup sekitar, yang menyebabkan lingkungan yang tidak sehat dan ketidaknyamanan. hidup, udara yang tidak sehat bahkan menyebabkan penyakit dan banjir yang sangat merugikan banyak orang. (hasil Wawancara, Siswa Yudistira Arif kelas II, Oktober 2019)

Yusdistira Arif mengatakan Jikalau mampu, seseorang bisa mengolah sampah menjadi bank sampah sehingga bisa di daur ulang oleh pabrik daur ulang dan tentunya akan menghasilkan nominal bagi masyarakat.

Berbagai macam video yang dihasilkan siswa sebagai aspirasi mereka untuk menyampaikan pemikiran mereka. Selain video Yusdistira Arif ada juga video cover sebuah lagu yang merdu didengar, dengan tujuan untuk mengapresiasikan bakatnya dalam bidang seni suara dan ingin menghibur orang banyak dengan lagu- lagu yang dicover oleh siswa. Tujuan siswa mempublikasikan Vlog adalah untuk memberikan inovasi kepada penikmat Vlog dan memberikan motivasi sehingga siswa mampu untuk menyalurkan bakat mereka di dunia media sosial.

Manfaat yang kita dapatkan dari penggunaan media sosial, salah satunya dari penggunaan Vlog, bahkan siswa sangat merasakan betapa pentingnya penggunaan media sosial. Siswa banyak mendapatkan ilmu pengetahuan dan informasi seperti bahan tugas sekolah yang mereka tidak ketahui dan dapat belajar dari Vlog yang ada.

Sebagai pengunggah Vlog, siswa SMK Darussalam menyukai Vlog yang berbeda beda. Beragam kriteria Vlog sesuai dengan kebutuhan pengguna Vlog sudah ada di publikasikan pada YouTube. Ada siswa yang menyukai content Vlog mengenai tutorial, kuliner, Frank (Jebakan), game, seni musik, ceramah ustadz, politik dan sebagainya. Dengan kriteria dan rasa suka siswa terhadap sesuatu hal membuat mereka mampu menciptakan sebuah video sehingga bakat dan kreasi mereka tersalurkan.

Memperkenalkan profil SMK TIK Darussalam merupakan salah satu dari kreasi siswa, dengan menampilkan visi, misi, sarana dan prasarana, kegiatan Inti dan ekstrakulikuler yang ada di sekolah, menjadi suatu video yang menyajikan profil sekolah sehingga masyarakat baik yang sudah mengenal atau bagi yang belum mengetahui SMK TIK Darussalam mendapatkan Informasi lebih banyak dan menjadi daya tarik tersendiri bagi orang tua siswa untuk mendaftarkan anak-anak mereka untuk menjadi siswa di sekolah tersebut.

Dalam perkembangan Vlog yang sangat pesat, media sosial banyak menyajikan beragam pengetahuan dan beragam Informasi penting yang sangat membatu kita dalam aktivitas sehari-hari, Khususnya pada siswa SMK TIK Darussalam sangat menyadari betapa pentingnya menggunakan media sosial sebagai sarana untuk mendapatkan ilmu pengetahuan sesuai dengan kebutuhan mata pelajaran di sekolah, sangat membantu mereka mencari solusi dan 
jawaban dari tugas sekolah yang diberikan oleh guru,

Materi pelajaran yang dibutuhkan, tidak sulit lagi diperoleh, bahkan tidak harus membeli buku, siswa dengan mudahnya mendapatkan informasi dari media sosial seperti google, jurnal, dan mengunggah buku sehingga siswa tidak sulit lagi untuk membeli buku. Salah satu siswa pengguna Vlog juga bisa memperoleh informasi tentang pembelajaran mereka di sekolah sesuai dengan kebutuhan mereka di sekolah, mampu mengasah bakat dan menimbulkan keberanian dan kepercayaan diri mereka untuk menciptakan suatu Vlog yang positif.

Vlog yang memiliki beragam video mengenai ilmu pengetahuan dengan kemampuan mereka masing-masing, siswa kreatif dengan mempublikasikan Vlog yang memiliki Exposure, bagaimana cara menggunakan alat- alat teknik Informatika seperti kamera digital, dan cara edit kamera untuk menghasilkan foto atau video yang memiliki koreografi yang jernih dan berkualitas. Diharapkan mereka bisa praktik secara langsung dan semakin memahami suatu bidang ilmu tertentu dengan praktik yang di sampaikan melalui Vlog.

Konten video di kalangan SMK TIK Darussalam menjadi hiburan dan pembelajaran bagi mereka khususnya kelas multimedia. Di mana pola pikir mereka akan dipacu untuk terus memikirkan apa yang mau mereka bagi kepada diri mereka sendiri dan orang banyak melalui Vlog.

Di balik kemudahan dalam mengakses youtobe, terdapat banyak dampak positif yang diperoleh siswa ketika mereka mencoba membuat Vlog. Menambah wawasan dan pengetahuan, mereka mendapatkan pengalaman baru dalam hal interaksi dengan orang-orang yang mereka temui, menjadi pribadi yang bijaksana dalam memilih hal baik dan tidak untuk mereka lakukan.

Siswa/siswi di SMKS TIK juga merasa jika penggunaan media social Vlog memiliki dampak positif dan negatif. Pada dasarnya fungsi positif lebih banyak dapat dirasakan oleh pengguna Vlog. Pada media sosial terlebih lagi bagi siswa yang sangat membutuhkan banyak informasi untuk memenuhi kebutuhan, untuk mendapatkan banyak ilmu dengan melihat langsung praktikum dari Vlog. Siswa langsung dapat mendengar dan melihat langsung ilmu yang di butuhkan dan dengan mudahnya dapat memahaminya untuk membantu proses belajar di sekolah. Dampak negatif yang dirasakan pengguna Vlog sekarang semakin banyak, akibat adanya orang-orang yang tidak bertanggung jawab dalam mempublikasikan video mereka dan di tonton oleh banyak orang. Kebijaksanaan kita sebagai masyarakatlah, orang tua, guru yang dituntut untuk dapat memilih video Vlog mana yang baik dan tidak baik untuk diperlihatkan kepada generasi muda.

\section{SIMPULAN}

Peran Media sosial (YouTube) dengan konten Vlog dalam memberikan informasi baik dalam pelajaran (khususnya dalam dunia pendidikan), membuat siswa mengetahui banyak hal dan memberikan perkembangan pola pikir siswa dalam menambah wawasan dan memperoleh informasi. Informasi yang diberikan sangat membantu mereka dalam sistem belajar di sekolah. Di samping itu bukan hanya seputar pelajaran saja tetapi juga 
pengetahuan-pengetahuan terbaru yang sedang hangat di perbincangkan. Serta yang membuat siswa dapat berpikir maju dan mampu mengikuti perkembangan dunia dari Vlog tersebut.

Informasi yang diperoleh dari media sosial Vlog tentunya tidak akan berdampak buruk terhadap siswa, jika Vlog yang di konsumsi memiliki video yang positif. Seperti Vlog mengenai informasi pendidikan atau tutorial dalam bidang pendidikan, bahkan Vlog kreasi seseorang yang mampu mempengaruhi penonton untuk menciptakan kreasi baru yang sangat membangun dalam kegiatan positif. Namun, ketika siswa tersebut memperoleh Vlog negatif, dari Vlog tersebut membuat siswa jadi mengetahui contoh-contoh hal yang tidak baik. Yang nantinya di khawatirkan adalah siswa terpengaruh untuk melakukannya. Sehingga akan ada dampak yang sangat buruk bagi pengguna Vlog yang memiliki content negatif, ini sangat merugikan bagi siswa dan publik yang mengkonsumsi Vlog yang tidak baik.

\section{DAFTAR PUSTAKA}

Ahmadi, R. (2014). Metodologi Penelitian Kualitatif, Jakarta: Ar-Ruzz Media

Barus, R.K.I.., (2015), Pemberdayaan Perempuan melalui Media Sosial, Jurnal Simbolika: Research and Learning in Comunication Study, 1 (2): 118-128
Cangara, H. (2002). Pengantar Ilmu Komunikas, Jakarta: Gramedia Widisarana.

Darmawan, D. (2013). Pendidikan Teknologi Informasi dan Komunikasi, Bandung: PT. Remaja Rosdakarya.

Heryanto, G. (2015) Media Komunikasi Politik: Jakarta: Ircisod.

Kurniawati, D. (2017). Dampak Ketergantungan Remaja terhadap Media Sosial dan Upaya Mengantisipasi, Jurnal Simbolika: Research and Learning in Comunication Study. 3(1): 11-21

Liliweri, A, (2012), Komunikasi Verbal dan Nonverbal, Bandung: Citra Aditya Bakti.

Lubis, F.R.A., Suharyanto, A., Effendy, R., Meidasari, V.E., Shahnaz, L. (2020). Role of Facebook Advertising in Promoting Tourism in Asia. International Journal of Psychosocial Rehabilitation

Mulyana, D. (2002). Ilmu Komunikasi: Suatu Pengantar, Bandung: PT. Remaja Rosdakarya.

Nurudin, (2007). Perkembangan Teknologi Komunikasi, Jakarta: Rajawali Pers.

Onong, U.E, (2003). Ilmu, Teori \& Filsafat Komunikasi, Bandung: Citra Aditya Bakti.

Rahmat, J. (2004), Metode Penelitian Komunikasi, Bandung: PT. Remaja Rosdakarya.

Singarimbun, M, (1995), Metode Penelitian Survey., Jakarta: LP3ES.

Sugiyono. (2007). Memahami Penelitian Kualitatif, Bandung: Alfabeta.

Survey peminat Vlog, CNN Indonesia.com diunduh tanggal 16 Oktober 2019.

Syaroh, M. (2018). Keterlibatan Radio Republik Indonesia (RRI) Medan dalam Mewujudkan Partisipasi Perempuan Sebagai penyiar dan Reporter dalam program penyiaran. Majalah Ilmiah Politeknik MBP

West Richard \& Turner. Lynn H, (2011). Pengantar Teori Komunikasi Analisis dan Aplikas, Jakarta: Salemba Humanika

Widjaja. W. A., (1986), Komunikasi: dan Hubungan Masyarakat, Jakarta: Bina Aksara 